\title{
Ciudad educadora: didáctica del patrimonio cultural de los derechos humanos desde una perspectiva controversial. Orientaciones metodológicas de enseñanza y aprendizaje del pasado reciente en el contexto curricular chileno
}

\author{
Educating City: Didactic of the cultural heritage of Human Rights from \\ a controversial perspective. Methodological guidelines for teaching and \\ learning from the recent past in the chilean curriculum context \\ Dra. Carolina Aroca Toloza ${ }^{a} \&$ Prof. Carolina Maturana Ibáñez \\ ${ }^{a}$ Académica Departamento de Educación, Universidad de Chile \\ $\measuredangle$ carolina.aroca@u.uchile.cl [orcid.org/0000-0002-5006-1616]

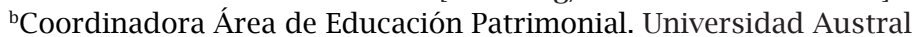 \\ carolina.maturana.iba@gmail.com [orcid.org/0000-0003-0407-6734]
}

\section{RESUMEN}

La siguiente comunicación tiene por objetivo elaborar un conjunto de orientaciones de enseñanza del patrimonio cultural de los Derechos Humanos a través de la articulación teórica y metodológica de la ciudad educadora, los derechos humanos y didáctica del patrimonio cultural desde un enfoque controversial. Se propone una metodología cualitativa a través del uso de fuentes secundarias que para los efectos de esta propuesta, se centrará en: ¿cuáles son las orientaciones didácticas del patrimonio cultural que permiten la enseñanza de los Derechos Humanos para favorecer las ciudadanías memoriales y responsables del pasado reciente heredado? Se constata la necesidad de proponer un tratamiento articulado entre el saber académico y el conocimiento social, potenciando entre los y las estudiantes el desarrollo de aprendizajes para asegurar la salvaguardia consciente de los lugares de memoria desde una ciudadanía activa.

PALABRASCLAVE: ciudad educadora, pasado reciente, patrimonio, derechos humanos, enfoque controversial.

\section{ABSTRACT}

The aim of the following communication is developing a set of guidelines for teaching the cultural heritage of human rights. It is possible through the theoretical and methodological articulation of the pedagogical approaches of the educating city, human rights and didactic of the cultural heritage from a controversial approach. 
A qualitative methodology is proposed through the use of secondary sources with focus on: ¿what are the didactic orientations of the cultural heritage that allow the teaching of human rights in favor of the memorial and responsible citizenships for the inherited recent past?

There is a need to propose an articulated treatment between academic and social knowledge. This controversial view promote in the students the development of conscious learning to ensure the care of memory places from an active citizenship.

KEY WORDS: Educating city, recent past, heritage, human rights, controversial approach.

\section{INTRODUCCIÓN}

La siguiente comunicación tiene por objetivo elaborar un conjunto de orientaciones de enseñanza del patrimonio cultural de los Derechos Humanos a través de la articulación teórica y metodológica de la ciudad educadora, los derechos humanos y didáctica del patrimonio cultural desde el enfoque controversial como alternativa pedagógica, la que permite analizar los derechos fundamentales, sus tensiones y problemas, relevando conflictos y controversias en temas que involucran el contexto y vidas personales y cotidianas, tanto de los/as educadores/as como de los/as estudiantes, lo que se constituye en un desafío educativo que favorece un rol ciudadano activo (Magendzo \& Pavez, 2018). Del mismo modo, la propuesta busca ampliar el conocimiento de las distintas dimensiones que componen el campo de los Derechos Humanos y su materialización espacial en la ciudad, vale decir, favorecer el reconocimiento, apropiación y recreación de acciones favorables a una convivencia pacífica desde los sitios y lugares que conservan y narran las experiencias de vulneración y/o defensa de Derechos Humanos como el Parque por la Paz Villa Grimaldi; Sitio Histórico Hornos de Lonquén; Sitio Histórico José Domingo Cañas; Sitio Histórico de la Matanza de Mulchén, Cuartel Almirante Silva Palma, Sindicato de Trabajadores de la Construcción, excavadores y alcantarilleros, entre otros (Seguel, 2018) en el contexto del pasado reciente chileno, a fin de promover la formación temprana y contextualizada de ciudadanías activas y memoriales entre las nuevas generaciones.

La justificación del tema de trabajo nace de la constatación de vacíos en las referencias educativas formales para tratar la enseñanza del pasado reciente desde la didáctica del patrimonio cultural vinculada a los derechos humanos, lo que ha llevado a muchos docentes a perpetuar una noción monumentalista de la historia y conservacionista del patrimonio, producto de la separación artificial entre historia y memoria. Se propone una metodología cualitativa que permita rastrear el uso de fuentes secundarias y los conceptos jerarquizados en la formulación de la problemática. Se constata la necesidad de proponer un tratamiento articulado entre el saber académico y el conocimiento social, potenciando entre los y las estudiantes el desarrollo de aprendizajes significativos (empatía y pertenencia) para asegurar 
la salvaguardia consciente de los lugares de memoria desde una ciudadanía activa, lo que se materializa en una propuesta didáctica de los derechos humanos desde la perspectiva patrimonial. El objetivo general de la investigación es: Diseñar orientaciones disciplinares y pedagógicas en torno al campo del Patrimonio Cultural para la enseñanza de los Derechos Humanos vinculados a la memoria histórica del pasado reciente, en espera de contribuir a la formación de ciudadanías activas y memoriales en la escuela. Y los objetivos específicos son 1) Definir los aspectos socio-culturales de las Sociedades del Conocimiento que fundamentan el uso del Patrimonio Cultural para la enseñanza y aprendizaje de los Derechos Humanos; 2) Analizar el tratamiento disciplinario de las nociones de pasado reciente, patrimonio cultural, Derechos Humanos, ciudad educadora y ciudadanía presente en el enfoque de la pedagogía de la memoria; 3) Establecer orientaciones de enseñanza que promocionen el uso de patrimonio cultural para la enseñanza de Derechos Humanos vinculados a la memoria histórica reciente en el subsector de Historia, Geografía y Ciencias Sociales.

\section{METODOLOGÍA}

El estudio se inscribe en un enfoque cualitativo interpretativo, que permite la comprensión y los sentidos de la enseñanza de los Derechos Humanos en el currículo escolar chileno, considerando los aportes teóricos de las políticas de Derechos Humanos, los enfoques pedagógicos de la ciudad educadora y la didáctica del patrimonio cultural.

La propuesta de investigación propone un permanente diálogo entre las matrices disciplinarias derivadas de las Ciencias Sociales que definen, promueven y evalúan la memoria histórica del pasado reciente, la didáctica del patrimonio vinculado a los derechos humanos y lugares de memoria. Se propone una metodología cualitativa que permita indagar en el uso de fuentes secundarias, los conceptos jerarquizados en la formulación de la problemática en cuestión, que para los efectos de esta propuesta se centrará en la siguiente pregunta de investigación: ¿Cuáles son las orientaciones didácticas del Patrimonio Cultural que permiten la enseñanza de los Derechos Humanos para favorecer las ciudadanías memoriales y responsables del pasado reciente heredado?

A modo de supuesto inicial se reconoce una dinámica relación entre Derechos Humanos y el Patrimonio Cultural respaldada tanto por las normativas internacionales vigentes en el área de Derechos Humanos, Comisión Derechos Humanos, ONU (2005); Corte Interamericana de Derechos Humanos CIDH (2009-2010); Asamblea General de la Organización de Naciones Unidas, ONU (2005), Declaración Universal de los Derechos Humanos (UNESCO), así como por la implementación paulatina de políticas públicas multisectoriales de carácter nacional e iniciativas locales de educación intercultural con uso de Patrimonio Cultural. En este sentido, se identifica el potencial formativo de los artefactos de memoria (patrimonio) por encontrarse vinculados a las representaciones simbólicas de las pertenencias y las narrativas colectivas, entendiéndose como articulador de las experiencias sociales del pasado y el 
futuro, favoreciendo una actualización efectiva de las oportunidades y desafíos existentes en el campo de los Derechos Humanos dentro de las escuelas.

La aplicabilidad a escala local de estas realidades humanitarias requiere de acciones concretas en favor del conocimiento, valoración, protección y promoción de los Derechos Humanos, impulsadas por una agenda ciudadana activa (diálogo permanente entre instituciones públicas, privadas y civiles) con el objetivo de fortalecer las prácticas democráticas y desarrollar capacidades éticas que posicionan en el presente, una alta carga empática sobre las experiencias de sujetos que vivieron los contextos de violencia y defensa del valor humano en el periodo dictatorial que aborda desde el 11 de Septiembre de 1973 hasta el 11 de marzo de 1990, a través del establecimiento de la Junta Militar, la que toma el poder político marcado por un fuerte autoritarismo y caracterizado por practicar una amplia represión política que estuvo a cargo de la Dirección de Inteligencia Nacional (DINA) creada explícitamente con fines de represión ilícita, a través de desapariciones forzadas y violaciones a los Derechos Humanos en todo el país (Informe de la Comisión Nacional de Verdad y Reconciliación, Tomo 2, 1991).

Es en este contexto que se propone un ejercicio didáctico que potencie la enseñanza de los Derechos Humanos a través del Patrimonio Cultural vinculado a lugares de memoria, tomando como eje articulador y ejemplificador de la propuesta, la ciudad de Valparaíso.

Para efectos de la investigación se realizó una discusión bibliográfica inicial, permitiendo la construcción de una problemática central y el marco teórico referencial basado en el análisis de discurso de diferentes fuentes documentales. Permitiendo, en suma, definir las siguientes dimensiones de análisis: políticas públicas y sub-dimensión de políticas de la memoria, la cual comprende a los mecanismos legales y discursivos de elaboración de una memoria histórica compartida sobre el pasado reciente. Asimismo, en un segundo nivel de análisis, se tratarán los usos dados a la enseñanza del patrimonio cultural de los derechos humanos en el currículum nacional, considerando los objetivos y aprendizajes esperados. Finalmente, se presentará un conjunto de orientaciones didácticas para el trabajo en Derechos Humanos, considerando un modelo de secuencia pedagógica. A continuación se presenta categorización por Dimensiones Subdimensiones y Categorías de análisis de discurso de fuentes bibliográficas.

En lo central, el planteamiento considera la confección de una matriz didáctica desde tres ejes metodológicos orientadores:

i) Contextualización del ejercicio de enseñanza.

ii) Enfoque disciplinar y marco conceptual (tratamiento a las nociones disciplinares).

iii) Aspectos procedimentales que consideran el marco curricular vigente para una propuesta didáctica del Patrimonio Cultural de los Derechos Humanos (conclusiones). 
Tabla 1. Categorías de análisis de discurso fuentes bibliográficas.

\begin{tabular}{|c|c|c|}
\hline DIMIENSIONES & SUB DIMENSIONES & UNIDADES DE ANÁLISIS \\
\hline \multirow{5}{*}{ Políticas públicas } & \multirow{5}{*}{ Políticas de la memoria } & $\begin{array}{lll}\text { Informes } \quad \text { Comisiones } & \text { de } \\
\text { Reconciliación y Verdad } & \end{array}$ \\
\hline & & $\begin{array}{l}\text { Ministerio de } \text { Educación- } \\
\text { Currículum Nacional }\end{array}$ \\
\hline & & $\begin{array}{l}\text { Consejo Nacional de } \\
\text { Monumentos } \\
\text { Ley de Monumentos }\end{array}$ \\
\hline & & $\begin{array}{l}\text { Instituto de Derechos Humanos } \\
\text { (informes-orientaciones) }\end{array}$ \\
\hline & & $\begin{array}{l}\text { Ministerio de las Culturas, las } \\
\text { Artes y el Patrimonio - Unidad de } \\
\text { Memoria y Derechos Humanos }\end{array}$ \\
\hline \multirow{5}{*}{$\begin{array}{l}\text { Usos del Patrimonio } \\
\text { Cultural de los } \\
\text { Derechos Humanos }\end{array}$} & \multirow{2}{*}{ Espacio escolar } & Planes y Programas de Estudio \\
\hline & & Textos escolares \\
\hline & \multirow{3}{*}{ Agencias de memoria } & $\begin{array}{l}\text { Museo de la Memoria y los } \\
\text { Derechos Humanos }\end{array}$ \\
\hline & & Sitios de conciencia \\
\hline & & Organizaciones civiles \\
\hline \multirow[t]{3}{*}{$\begin{array}{c}\text { Didáctica del } \\
\text { Patrimonio Cultural } \\
\text { de los Derechos } \\
\text { Humanos }\end{array}$} & $\begin{array}{l}\text { Estrategias } \\
\text { Pedagogía de la Memoria } \\
\text { (para qué-qué-cómo) }\end{array}$ & $\begin{array}{l}\text { (Para qué) contextualización del } \\
\text { problema de enseñanza. } \\
\text { ¿Qué? } \\
\text { Pasado reciente } \\
\text { Memorias } \\
\text { Patrimonio controversial } \\
\text { Derechos Humanos } \\
\end{array}$ \\
\hline & $\begin{array}{l}\text { Enfoque de la ciudad } \\
\text { educadora. }\end{array}$ & $\begin{array}{l}\text { Aprender la ciudad como } \\
\text { contenido (articulación de lugares } \\
\text { y sitios de memoria) }\end{array}$ \\
\hline & Propuesta didáctica ¿Cómo? & $\begin{array}{l}\text { Ruta de memorias y patrimonio } \\
\text { de los derechos humanos }\end{array}$ \\
\hline
\end{tabular}

Fuente: Elaboración propia.

\section{CONTEXTUALIZACIÓN DEL EJERCICIO DE ENSEÑANZA Y APRENDIZAJE. MARCOS DE ACTIVACIÓN DEL PATRIMONIO CULTURAL DE LOS DERECHOS HUMANOS DESDE UNA PERSPECTIVA CONTROVERSIAL}

La propuesta responde a las exigencias actuales de la formación escolar en la escena de las sociedades del conocimiento, quienes viven una cultura histórica basada en el pleno acceso a la información sobre el tiempo pasado, sin embargo, producto de la aceleración se han desarrollado débilmente las capacidades cognitivas, procedimentales y ciudadanas que permitan observar, comprender y construir conocimiento histórico 
genuino. Lo anterior, puede agudizarse, cuando hablamos de pasado reciente, en razón que posee otra disposición, requerimientos y emergencias.

Enseñar la memoria significa hablar del pasado, del presente y del futuro. La defensa de los valores de la paz y de la democracia nos pide establecer una relación más nítida entre el pasado y nuestro futuro. "Nuestra preocupación es que a través de una lectura crítica de los acontecimientos de la Shoah, podamos comprender mejor los peligros, los genocidios y los horrores actuales” (Pagés, 2008, p. 49).

Resulta vital, en este sentido, promover una historia con memoria para incorporar al código disciplinar del patrimonio cultural de los Derechos Humanos, las experiencias y vivencias materiales cercanas (ampliando las nociones de los propios derechos) sobre aquellos protagonistas de los procesos sociales de los pasados excluidos de la oficialidad, declarados anónimos o carentes de "importancia” (Cuesta, 2003, p. 103).

La escuela continúa ocupando un lugar privilegiado en la formación de ciudadanías, por estructurar lógicamente -narrativas- y transmitir valores comunes ajustados a la construcción de identidades colectivas -imágenes-. La enseñanza de la historia con memoria cumple un rol clave, en razón de la relevancia que adquiere el tiempo pasado en las representaciones sociales, las cuales, direccionan el marco de las decisiones colectivas. El acceso al pasado desde otras entradas, nos permite ampliar las voces que participan en el horizonte de historicidad del presente, favoreciendo la enseñanza de una ciudadanía en un sentido activo y heterogéneo, respetuoso de las diferencias identitarias y dialogantes con las generaciones que han producido y recreado los recuerdos colectivos (Jelin, 2002).

Abordar los Derechos Humanos desde la perspectiva controversial significa mostrar cómo estos derechos, en algunos momentos se tensionan entre sí, como señalaran Magendzo y Pavez (2018, p. 141): "El supuesto es que aprender y analizar la DUDH desde esta perspectiva permite crear en el aula un espacio de diálogo, de confrontación argumentada y racional de ideas, de cuestionamiento e indagación de posiciones". La enseñanza de los Derechos Humanos, entonces, no se agota en la transmisión de contenidos políticos jurídicos, sino en su aplicabilidad a la problemática en la vida cotidiana. La controversialidad resulta una oportunidad pedagógica para potenciar la participación ciudadana temprana en los asuntos públicos, dotando a los estudiantes de un marco de derechos y responsabilidades para profundizar la convivencia democrática.

En efecto, la enseñanza de los Derechos Humanos desde un enfoque controversial tiene como propósito asumir una postura horizontal y dialógica entre quien enseña y quien aprende, asumiendo una bidireccionalidad del proceso educativo, es decir, uno aprende del otro, en un espacio y contexto de aprendizaje democrático.

Es así que ciudad, derechos humanos y patrimonio, convergen en un territorio común, la herencia cultural, la memoria, el pasado reciente y la educación ciudadana se 
manifiestan, expresan y concretizan de manera material e inmaterial en sitios, lugares y objetos de memoria, así como en actitudes y acciones realizadas por personas. En este marco, nos parece pertinente la propuesta de antipatrimonio (Martín-Cáceres, 2018 en Estepa, 2018) como un subtipo de lo que se entiende como patrimonio en conflicto, denominación que refiere a cuando el docente selecciona elementos patrimoniales con énfasis en las diversas causas que provocan el conflicto, ya fuese por su carácter ideológico, político, medioambiental o por la interacción entre aquellos. Es así que con la enseñanza del antipatrimonio se intenta no olvidar las brutalidades cometidas en los conflictos violentos entre ciudadanos de un país o con otros países, con el objetivo de establecer vínculos emocionales con las víctimas de esas atrocidades, personas torturadas, asesinadas, ejecutadas o exiliadas, a través de visitas presenciales, rutas patrimoniales, historias orales , análisis de documentación gráfica, escrita y audiovisual, así como de visitas a museos de Memoria, centros de interpretación, entre otros.

En consecuencia, la propuesta de análisis se inscribe en el marco temporal de pasado reciente, el cual busca abordar las experiencias de violencia política, sufrimiento y exterminio acontecidos en el transcurso del siglo XX en Chile, en específico durante la Dictadura Militar.

La historia en tanto forma de memoria legítima ha sido capaz de producir narraciones para elaborar las representaciones del pasado, las cuales requieren del registro e intensidad de imágenes fundadas por las memorias individuales y colectivas, por ello, en el campo del pasado reciente se ha "constituido el recuerdo como un objeto y fuente de conocimiento ordenado a recuperar las voces de sectores silenciados y a cuestionar la historia nacional tradicionalmente concebida desde los archivos, la cual se abre hacia una confrontación con la memoria” (Rubio, 2013, p. 376). El auge dado a la interdependencia entre memoria e historia posiciona a la cultura histórica no sólo como un producto de los sentidos disciplinarios de la historia, sino más bien, en el punto de unión entre los conceptos historiográficos, valoraciones socioculturales sobre el tiempo y de la relatividad de expectativas memoriales de las sociedades, las que en suma han permitido a los grupos humanos tomar decisiones por un sentido u otro (Gadamer, 1993). La cultura histórica, al tratar las dimensiones ignoradas -lo no dicho- por la reflexión objetiva del tiempo, visualiza los marcos interpretativos que dirigen las acciones de recuerdo y olvido, y los contenidos propios de la conmemoración: "una manera particular de abordar interpretativamente el tiempo, precisamente aquella que resulta en algo como 'historia' en cuanto contenido de la experiencia, producto de la interpretación, medida de orientación y determinación de la finalidad" (Rüsen, 2009, p. 20).

El fenómeno patrimonial, a su vez, comprende al resultado de un proceso de legitimización simbólica capaz de activar memorias visibles o subterráneas depositadas en el espacio público. El propósito de activación de ciertos repertorios patrimoniales es constituir referencias identitarias que faciliten la legitimidad a través del consenso y/o 
la coerción. "La eficacia simbólica depende de muchos factores, entre los cuales están la contextualización de los símbolos en prácticas y discursos y el nivel de consenso de que gocen referentes y significados” (Prats, 1998, p. 29).

Las posibilidades de promoción del patrimonio dependerán del desarrollo de la cultura histórica del grupo que lo reconoce, esto implica una importante transformación en la comprensión pública del pasado y en los caminos interpretativos de los actos conmemorativos, vale decir, se instala la pregunta por el sujeto recordante, por los contenidos del recuerdo, por el lugar y el tiempo en que se recuerda. De esta forma, se revitaliza la acción de puesta en valor de los bienes patrimoniales dentro del proceso de activación de la memoria social, para reconocer el lugar protagónico del sujeto social en la legitimidad de ciertos repertorios identitarios, lo cual nos amplía la panorámica sobre cómo entender el patrimonio pensando en la escuela como "un conjunto de bienes materiales e inmateriales, que constituyen la herencia de un grupo humano y que refuerzan emocionalmente su sentido de comunidad con una identidad propia y que son percibidos por otros como característicos" (Aroca, 2017, p. 34).

El patrimonio, de esta manera, se manifiesta como una construcción social sujeta a tres principios claves para su activación y apropiación significativa: herencia en la manifestación tangible del tiempo histórico, aquellos pedazos de pasado que tenemos presente y que en condición de sujetos sociales podemos abordarlos emocional, racional y políticamente a fin de promover la cohesión grupal (fuente testimonial del pasado en el presente); significación en condición de los grados de apropiación producida por los agentes que emiten y recepcionan la herencia en clave identitaria, vale decir, las interpretaciones simbólicas desarrolladas por el presente sobre los dispositivos del pasado (documento de identidad) y participación, se vincula de forma inalienable al patrimonio con la sociedad que lo produce y reproduce, en tanto vinculación con el pasado, resignificación de experiencia vivida o heredada, y la recreación utilitaria de los repertorios memoriales. Los marcos identitarios resultan activados por las personas y no por las instituciones, por ello su valor no está determinado por su singularidad, sino por su significado: la función social que se le otorga en el presente (Maturana, 2017).

Asimismo, los marcos de memoria orientados en, desde y para los Derechos Humanos, permiten proporcionar dinamismo a la noción de patrimonio cultural al caracterizar las experiencias de hombres y mujeres en un mismo estatus de sujeto histórico (dignidad y valor de la persona humana), reforzar los ejes interpretativos de la violencia que han abordado históricamente la dualidad de víctimas y victimarios (más allá de la corporalidad del trauma), manifestar "lo político" como experiencia cotidiana -repetible y contemporánea- y ampliar la noción de fuente testimonial hacia una experiencia social compartida, propiciando en suma, una responsabilidad ética de la sociedad ante la memoria del dolor excluida de los relatos históricos oficiales. Es importante, en tal caso, promover un marco de Derechos Humanos considerando las 
distintas generaciones que lo componen, tales como son: derechos de primera generación -políticos y civiles-, segunda generación -económicos, sociales y culturales-, tercera generación -de los pueblos- y cuarta generación -derecho a la memoria-.

\section{RESULTADOS}

Con relación a la dimensión del patrimonio controversial en la subdimensión del espacio escolar, la revisión del Marco Curricular de Educación General Básica en su versión 2002, actualización 2009 y posterior actualización denominada Bases Curriculares, 2013, aún se aprecia una carencia de objetivos y contenidos explícitos, referidos al ámbito Patrimonial los que, más bien subyacen o son tratados de manera general en los textos educativos.

Ahora bien en específico los temas de identidad, memoria y patrimonio se enuncian brevemente y hablar de memoria vinculada a derechos humanos es prácticamente inexistente (Matriz Curricular Básica, 2002; Actualización 2009 y Bases Curriculares, 2013). Consecuentemente con lo anterior, la temática patrimonial, comienza a introducirse en el currículo escolar de la Enseñanza General Básica, por un lado, de manera incipiente y extremadamente implícita.

En el año 2016 se promulga la Ley NÚM. 20.911 que Crea El Plan de Formación Ciudadana para los Establecimientos Educacionales reconocidos por el Estado, estos planes tienen como objetivo que cada escuela y liceo diseñe acciones que permitan a las y los estudiantes participar de procesos formativos -curriculares y extraprogramáticoscuyo centro sea la búsqueda del bien común. Es decir, vivenciar el respeto, la tolerancia, la transparencia, la cooperación y la libertad; la conciencia respecto de sus derechos y responsabilidades en tanto ciudadanos (Ministerio de Educación. División de Educación General. Orientaciones para la elaboración de un Plan de Formación Ciudadana, 2015). En este marco el Ministerio de Educación elaboró dos documentos de Orientaciones e Instrumentos de Evaluación Diagnóstica Intermedia y Final en Formación Ciudadana para los $3^{\circ}$ y $4^{\circ}$ medios, en los que presenta la temática de "Problemas globales, desafíos locales Los Derechos Humanos" en los que se desagregan los tópicos de Educación para los Derechos Humanos; Definición de los Derechos Humanos; Promoción y supervisión de los Derechos Humanos: visión institucional. Si bien están presentes los contenidos, estos son presentados como temas propuestos a desarrollar por el establecimiento educacional pero no como temáticas en sí mismos, sumado a que se constituyen en orientaciones amplias en los que cada institución es libre de introducirlos o no en su proyecto educativo, así como del plan de formación ciudadana de la institución escolar.

En esta misma línea y a modo de ejemplo, en las Bases Curriculares 2013, de segundo medio, se presenta dentro de la propuesta de organizadores temáticos la "Dictadura militar, transición política y consenso en torno a la democracia en el Chile actual", en 
el cual el único objetivo vinculado de manera explícita a los Derechos Humanos es el primero: "Explicar que durante la dictadura militar se suprimió el Estado de Derecho y se violaron sistemáticamente los derechos humanos, reconociendo que hubo instituciones civiles y religiosas que procuraron la defensa de las víctimas” (p. 62) en este objetivo se puede apreciar que no se desarrollan aspectos de mayor profundidad sobre violaciones sobre Derechos Humanos, en cuanto a su problematización, las luchas políticas para la recuperación de la democracia, se integra el concepto de Gobierno Militar, lo que evidencia un discurso ideológicamente sesgado.

Lo anterior se reafirma en el análisis efectuado por Pagés y Marolla (2018) en el que señalan que: "El currículum chileno, por tanto, resalta la descripción de acontecimientos históricos ligados a la política y la economía desde la visión oficial del gobierno, en ese momento partidos de la Concertación por la Democracia. En esta perspectiva de enfoque historicista no se problematizan los Derechos Humanos desde las violaciones, desapariciones y violencia acontecida durante la dictadura militar, por lo que no se promueve ni intencionan análisis más reflexivos y críticos sobre la historia del pasado reciente” (p. 167).

Resumiendo, en la marcha de nuestro proceso de indagación y descripción, se constató la existencia de múltiples referencias bibliográficas especializadas para tratar la memoria y el patrimonio: marcos conceptuales disciplinarios, reflexiones pedagógicas cercanas a la Educación Patrimonial, los marcos didácticos de las Ciencias Sociales y los enfoques de Formación Ciudadana. Sin embargo, las observaciones disciplinares no presentan una articulación de base con las prácticas de enseñanza, cada una de ellas problematiza los escenarios teóricos y metodológicos para potenciar sus propios campos de análisis, alejándose en suma, de la tarea central, la que consiste en construir puentes de diálogo entre los componentes disciplinares que permitan pensar la enseñanza del patrimonio en espacios educacionales formales para la formación de ciudadanía activa.

Cobra protagonismo, en este sentido, una verdad pública transmitida por los informes de Verdad y Reconciliación Rettig (1991) y Valech (2004), los cuales han delimitado las explicaciones sobre la crisis de la convivencia republicana a través de 3 tesis historiográficas de carácter causal: La primera tesis, denominada como Determinismo Histórico, sostiene la idea que el caos y la violencia llevaron a la crisis política y al Golpe de Estado; la segunda corresponde a la Decadencia republicana, que promueve una mirada Spengleriana del acontecer histórico del siglo XX, es decir, el desgaste de una cultura democrática sostenida en la lógica de los acuerdos políticos; y la última tesis, corresponde a la Guerra Fría, que justifica el Golpe de Estado y la violencia política por el contexto internacional de conflicto entre las potencias vencedoras de la Segunda Guerra Mundial EE.UU. y URRS (Rubio, 2013).

El currículum nacional desde el año 2009 incorpora esta tesis para la enseñanza de la historia reciente en los niveles de 6to básico y 3ro medio. Se delimita el periodo histórico entre los años 1960-1989, dividiendo en tres procesos específicos: crisis 
política, quiebre de la democracia y dictadura militar y recuperación de la democracia.

Los acontecimientos que sustentan la explicación histórica descansan en su mayoría en el escenario internacional: si la crisis es externa, los sectores políticos nacionales no tendrían responsabilidad en el desarrollo de las coyunturas. Esta afirmación promueve una visión débil de la ciudadanía, los Derechos Humanos como marco que funciona sólo en la defensa y una valoración negativa en la relación cambio social y violencia política.

En relación a una segunda dimensión del análisis, podemos decir que el uso de Patrimonio Cultural de los Derechos Humanos tiene presencia curricular en la actualidad en el área de Historia, Geografía y Ciencias Sociales, a través de dos instrumentos: Marco Curricular (1996/2009) y Bases Curriculares (2013). Bajo un modelo curricular por competencias, los estudiantes aprenden a hacer cosas, por sobre la retención de saberes enciclopédicos. Para alcanzar los saberes escolares específicos, el currículum por competencias propone el desarrollo de objetivos de aprendizajes (OA), los que se encuentran compuestos por una habilidad procedimental, el conocimiento conceptual y las capacidades ciudadanas. El aprendizaje es tratado en tres dimensiones: saberhacer-ser, pero será la habilidad procedimental el motor del quehacer, orienta a las otras dimensiones del aprendizaje. El saber haciendo dirige y moviliza los conceptos y las capacidades ciudadanas para que los estudiantes aprendan a resolver problemas concretos en el aula, y puedan movilizar al mediano plazo, los procesos de resolución aprehendidos a otras problemáticas de la vida.

Retomando lo anterior, los Objetivos de Aprendizajes que declaran el uso de los ejes de memoria social y patrimonio cultural se encuentran en los niveles de 2do, 5 to y 6to básico, y 2do, 3ro y 4to medio. A primeras luces, la memoria no se encuentra asociada al conocimiento patrimonial, y el pasado es recibido por el presente sin ejercicio de interpretación. El patrimonio sólo se caracterizó en el reconocimiento de las manifestaciones culturales preestablecidas como patrimoniales (catálogos UNESCO, Organización de las Naciones Unidas para la Educación, la Ciencia y la Cultura; Ministerio de las Culturas, las Artes y el Patrimonio; Consejo de Monumentos Nacionales) a través del desarrollo de habilidades de identificación, contemplación, conservación y valoración.

Ante una panorámica curricular conservacionista y descriptiva del patrimonio, difícilmente podríamos incorporar nuestro posicionamiento conceptual, didáctico y de formación de la ciudadanía, en razón que: i) el recurso patrimonial se establece desde una entrada monumental y anticuaria del pasado (fiestas por regiones, artesanías indígenas, edificios coloniales, etc.), en la cual las memorias históricas legitimadas por la historia nacional resultan activadas y validadas en el presente. A través de este recurso se produce una asimilación atemporal: el pasado y el presente no presentan diferencias constatables; ii) el patrimonio histórico se reconoce sólo en el acceso al pasado remoto -colonial-, asumiendo una valoración del pasado sólo por ser "antiguo" y "amenazado" por el paso del tiempo. 
Para el caso de pasado reciente, no se hace referencia a los sitios de memoria y la memoria social es incorporada como fuente de información complementaria al saber historiográfico; iii) las explicaciones históricas se construyen desde un régimen historicista, en el cual los acontecimientos del pasado se encadenan para justificar las condiciones del presente. Por lo cual, se condiciona el uso de memoria social, sólo como fuente de información relativa a los acontecimientos establecidos por la disciplina histórica. Los testimonios consultados bajo esta estructura son sometidos a los requisitos de veracidad impuestos por la historiografía, generando una limitación para abordar las experiencias contenidas en el recuerdo colectivo; iv) la aproximación al principio de herencia, el enfoque historicista que acompaña las explicaciones históricas, dificulta el tránsito crítico entre el pasado y el presente, si el presente se muestra como resultado de la acumulación de acontecimientos pasados, el patrimonio es el mensaje único del tiempo, por lo tanto, debe ser recibido como señal de aceptación a la tradición; v) en materia de significación, la identidad es incorporada en una variante nacional homogénea, sin hacer referencia a las diferencias culturales que se han desarrollado históricamente en los espacios regionales. La diversidad de experiencias territoriales es expresada a través del folclore y las tradiciones, dificultando, en suma, la apropiación significativa de las nuevas generaciones de la herencia del pasado; vi) participación, es comprendida en las prácticas tradicionales de la comunicación: los estudiantes son asociados a las acciones patrimonialistas en el rol de receptores de un mensaje del pasado que debe ser conservado en el presente, por lo tanto, la formación ciudadana se manifiesta en los ejercicios de cuidado y valoración de una catalogación patrimonial predefinida por otras instituciones; vii) la formación de la ciudadanía, se inscribe en un esquema tradicional del "deber ser ciudadano". Adopta un carácter contemplativo de la selección de acontecimientos memorables, el vínculo identidad-ciudadano conserva los rasgos culturales de la inclusión/exclusión, se acerca al valor del patrimonio para diferenciarse de otras comunidades recordantes, y para ritualizarlo en su calidad de antigüedad.

En la necesidad de promover iniciativas complementarias a los saberes conceptuales, procedimentales y las capacidades ciudadanas propuestas por el currículum nacional, creemos pertinente elaborar una propuesta de trabajo para la enseñanza del patrimonio cultural de los derechos humanos que aborden los ejes de pasado reciente y didáctica del patrimonio cultural para potenciar una formación ciudadana activa en el área de Historia y Geografía y Ciencias Sociales. En la Tabla 2 se presentan objetivos y actividades de aprendizaje identificados en los programas de estudios en diferentes cursos, tanto en Básica como en Media, en los que se aborda el patrimonio cultural y los Derechos Humanos.

En cuanto a la dimensión de enfoque de ciudad educadora, como proyecto de participación ciudadana, organizada, autónoma y solidaria, con sus instituciones educativas formales y no formales, se constata la inexistencia de este concepto debido a 
Tabla 2. Objetivos y Actividades de Aprendizaje vinculados a Patrimonio Cultural y Derechos Humanos.

\begin{tabular}{|c|c|}
\hline NIVEL & OBJETIVO DE APRENDIZAJE \\
\hline \multirow[t]{2}{*}{ 2DO BÁSICO } & $\begin{array}{l}\text { OA5 } \\
\text { Reconocer diversas expresiones del patrimonio cultural del país y de su } \\
\text { región, como manifestaciones artísticas, tradiciones folclóricas, } \\
\text { leyendas y tradiciones orales, costumbres familiares, creencias, idioma, } \\
\text { construcciones, comidas típicas, fiestas, monumentos y sitios históricos. }\end{array}$ \\
\hline & $\begin{array}{l}\text { OA9 } \\
\text { Reconocer diversas expresiones del patrimonio natural de Chile y de su } \\
\text { región, como paisajes, flora y fauna característica, y parques nacionales, } \\
\text { entre otros. }\end{array}$ \\
\hline $5 T O$ BÁSICO & $\begin{array}{l}\text { OA8 } \\
\text { Identificar, en su entorno o en fotografias, elementos del patrimonio } \\
\text { colonial de Chile que siguen presentes hoy, como edificios, obras de arte } \\
\text { y costumbres, entre otros. }\end{array}$ \\
\hline 6TO BÁSICO & $\begin{array}{l}\text { OA20 } \\
\text { Demostrar actitudes cívicas con acciones en su vida diaria, como: } \\
\text { Cuidar y valorar el patrimonio y el medioambiente (ejemplos: impulsar } \\
\text { y participar en campañas de reciclaje, realizar acciones en la casa y en } \\
\text { la escuela para ahorrar luz, agua y gas, etc.). }\end{array}$ \\
\hline 2DO MEDIO & $\begin{array}{l}\text { AE5 } \\
\text { Investigar sobre el desafio que planteó la celebración del centenario en } \\
\text { Chile y en América para desarrollar un balance del Centenario de la } \\
\text { Independencia. } \\
\text { Considerando: lectura e interpretación de información en distintas } \\
\text { fuentes: integración de información de diversas fuentes de análisis, } \\
\text { confrontación y reflexión a partir de variadas fuentes de información; } \\
\text { exposición de los resultados de investigación, de forma sintética y } \\
\text { organizada y utilizando diversos recursos elaboración de bibliografía. }\end{array}$ \\
\hline ЗRO MEDIO & $\begin{array}{l}\text { AE13 } \\
\text { Caracterizar los principales rasgos del golpe de Estado y de la dictadura } \\
\text { militar en Chile. Incluyendo: La violación sistemática de los Derechos } \\
\text { Humanos, la violencia política y la supresión del Estado de derecho. } \\
\text { Considera la recuperación de testimonios y expresiones de la memoria } \\
\text { social para indagar sobre contenidos del nivel y/o profundizar en la } \\
\text { experiencia de los sujetos que vivieron procesos históricos recientes. }\end{array}$ \\
\hline 4TO MEDIO & $\begin{array}{l}\text { OE } 16 \\
\text { Reconocer la presión que ejercen los procesos globalizadores sobre la } \\
\text { configuración espacial de las regiones de Chile, considerando ventajas, } \\
\text { impactos y resistencias locales tales como: rescate del patrimonio } \\
\text { histórico. }\end{array}$ \\
\hline
\end{tabular}

Fuente: Elaboración propia.

que es una concepción de participación ciudadana desconocida en el currículo escolar.

Por su parte, aprender la ciudad como contenido (Trilla, 1993), lo que implica asumirla como una fuente generadora de formación, socialización, interacción, es decir, como un entorno educativo capaz de producir aprendizajes por sí misma, siendo 
un agente informal de educación, no es conocido en Chile; lo que se hace es usar la ciudad como medio para motivar o reforzar algún contenido, en este sentido, existen las visitas pedagógicas, tales como visitar un museo, la biblioteca, instituciones sociales y comunitarias, aunque la mayoría de las veces son concebidas como paseos por los estudiantes ya que carecen de una intencionalidad pedagógica.

En este marco la didáctica del patrimonio surge como una propuesta intencionada, pues se basa en asumir y comprender que su importancia radica en favorecer en los estudiantes una comprensión del medio desde una construcción social, en la que diversos sucesos y acontecimientos han dejado testimonios y huellas a las generaciones presentes y futuras, por cuanto poseedores de una memoria histórica y cultural que les da sentido de identidad y pertenencia al grupo con su territorio.

La ciudadanía interpreta también el patrimonio desde los símbolos que son identificados en ese territorio urbano o rural, lo que permite entenderlo como un organismo vivo y por cierto leerlo como un texto, en el que se encuentra una diversidad de lugares y de hechos que brinda la posibilidad de preguntarse acerca de lo que ese lugar comunica, así entonces, estas dimensiones simbólicas y comunicativas son otros aspectos vinculados a una educación y didáctica patrimonial.

En esta misma línea y a partir del análisis efectuado para una didáctica del patrimonio controversial como un enfoque pedagógico crítico, la escuela puede contribuir a configurar las diferentes dimisiones vinculadas a la ciudadanía activa, llevando a los estudiantes a conocer el territorio urbano desde una perspectiva de análisis reflexivo que no se quede en la descripción superficial de él, sino que permita profundizar en sus diversos aspectos. La didáctica del patrimonio surge como una necesidad en el ámbito escolar, que debiera ser conocida y abordada por los profesores, y es en ese sentido que entre las diferentes estrategias que existen para conocer y aproximarse a este conocimiento del patrimonio proponemos las rutas patrimoniales.

El propósito de estas rutas es que la propia comunidad escolar identifique los lugares patrimoniales de su barrio, comuna y/o entorno escolar, que tengan un eje vertebrador en relación a contenidos, su historia, geografía, estética, entre otras, que permita darle un sentido a la ruta patrimonial. A través de la propuesta de ruta, efectuada por la comunidad educativa o curso, se promoverá el recorrido de los sitios de Derechos Humanos, aplicando una metodología didáctica asociada a actividades que permitan preparar la visita a los hitos identificados, realizarla de forma creativa en el lugar y luego trabajar la experiencia de la visita en el aula.

El objetivo del recorrido es que los estudiantes reconozcan, a través del/los sitio/s el significado in situ de los Derechos vinculados a una memoria cultural y colectiva del pasado reciente, problematizando en el objeto materializado en obra, los diferentes significados y sentidos de la misma, reconstruyendo la memoria a través de un enfoque ejemplificador (Todorov, 2000). 
1) Contextualización curricular: comprende a las adaptaciones intencionadas de los contenidos de enseñanza propuestos por el currículum nacional (saber oficial) para incorporar las experiencias vividas depositadas en el territorio local (saber marginado), a fin de experimentar la existencia de una diversidad de memorias que se encuentran depositadas en el espacio público, y que si bien, poseen un sentido territorial subjetivo (espacio y tiempo) son interpretadas bajo marcos sociales comunes que condicionan la organización y los sentidos que los recuerdos colectivos: facilitar un acceso crítico al pasado reciente desde el territorio.

2) El estudio de la realidad social y la acción en ella: el conocimiento que se adquiere de la experiencia territorial (recuerdo $u$ olvidos) tiene que ser retribuido a través de intervenciones que promuevan cambios sustanciales en la forma de habitar los lugares comunes. En este sentido, el enfoque de la ciudad educadora convoca a la escuela a aprender de la reflexión-acción para potenciar el desarrollo de ciudadanías activas y memoriales: desarrollar progresivamente capacidades para desplazarse en el tiempo con un sentido referencial de búsqueda (ETNOGRAFÍA).

3) Aprendizajes Basados en Proyectos (ABP): el desarrollo de proyectos escolares considera dos principios básicos del enfoque constructivista del aprendizaje: los conocimientos previos y la experiencia de los estudiantes. Los ABP representan una oportunidad para materializar el diálogo entre el saber aprendido y los nuevos conocimientos, con el objetivo de promover aprendizajes significativos, no sólo en relación a los conocimientos incorporados, sino también, a asignar un sentido diferente al acto de aprender. Ahora bien, la lógica de todo proyecto es alcanzar ciertos objetivos y resultados, dependiendo del contexto de intervención, el problema detectado, los recursos, los tiempos y el grupo humano que lo ejecute. Los proyectos escolares de intervención patrimonial tienen por propósito acercarse al conocimiento patrimonial para promover un vínculo referencial entre pasado y presente, en tal caso, se sitúa a los estudiantes ante problemas próximos de sus experiencias de vida en el territorio que habitan. Los proyectos escolares consideran la participación activa de los estudiantes en todas las etapas de desarrollo, considerando su labor como ejecutores y beneficiarios de los resultados esperados.

Considerando las referencias disponibles en esta materia, presentamos a continuación un modelo de proyecto escolar de intervención patrimonial y su implementación a través de dos ejes curriculares en el área de Historia, Geografía y Ciencias Sociales en los niveles de 6to básico y 3ro medio. 
a) Registro de los conocimientos previos y ajuste de la planificación inicial: En la fase inicial, el docente presentará la terminología básica que fundamenta los proyectos de intervención patrimonial: objetivos de conocimiento, resultados esperados, cronograma de trabajo, técnicas de trabajo colaborativo, evaluación según las fases y productos de la intervención. Los estudiantes dialogan participativamente sobre las responsabilidades grupales e individuales requeridas para llevar a cabo el desarrollo del proyecto. Asimismo, el docente utilizará esta instancia para recoger información relevante para el funcionamiento óptimo de su planificación, para ello, se sugiere el desarrollo de una evaluación diagnóstica sobre los vínculos pasado-presente que operan en la comunidad escolar, de forma que pueda establecer la organización de los principios de aproximación del patrimonio.

b) Delimitación del problema patrimonial del proyecto: Luego de analizar la evaluación diagnóstica, el docente recontextualiza su planificación en torno a las aproximaciones al patrimonio según las necesidades de aprendizajes de sus estudiantes. El proyecto de intervención tiene que ser caracterizado a través de una pregunta central que permita a los estudiantes acercarse al pasado a través de la indagación de fuentes documentales locales, y construir posibles respuestas fundamentadas.

c) Prospección territorial del problema central: De acuerdo al objetivo de aprendizaje contextualizado, la pregunta central vista en el punto anterior, será replanteada para estudiar la situación actual del territorio. En esta fase los estudiantes reconocen que el conocimiento patrimonial les permite transitar entre el pasado y el presente. Seleccionan colectivamente los aspectos que les interesa conocer del problema central situado en el territorio y los instrumentos de registro más pertinentes para esta tarea.

d) Análisis pasado-presente y trabajo de campo: En esta fase del proyecto se explora el territorio a través de herramientas de observación e instrumentos de registro etnográfico. Los estudiantes asumen el protagonismo en la mirada sobre la ciudad desde una óptica reflexiva que les permita reconocer las huellas del pasado en el presente, las formas materiales y los mensajes contenidos en los artefactos patrimoniales, y ausencia de otras memorias sociales. El profesor intenciona la observación a través del problema central del proyecto y en el registro de la observación con instrumentos de bitácoras, cartografías, fotografías, entrevistas, etc.

e) Propuesta de recreación de la memoria social en la ciudad: En la última fase del proyecto se revisan propuestas de actos de memoria que el grupo de estudiantes considere pertinentes y significativos para el territorio, según la experiencia de investigación llevada a cabo. De esta manera, se elabora participativamente un acto 


\section{CIUDAD EDUCADORA}

conmemorativo considerando la materialidad y el mensaje a heredar a las nuevas generaciones.

f) Evaluación: La evaluación corresponde a un proceso permanente de retroalimentación que permite al docente tomar decisiones pertinentes en el desarrollo del proyecto de intervención patrimonial. Se propone diversificar las estrategias de evaluación de acuerdo a los momentos de logro y dificultades para alcanzar el objetivo de aprendizaje, por ello, la propuesta considera la división del proceso evaluativo según los momentos del proyecto: diagnóstica (cuánto conocen), intermedia (cómo van) y sumativa (cuánto aprendieron). Los instrumentos de evaluación (rúbricas por desempeño complejo) serán aplicados en relación a los actores de aprendizajes, a través de la autoevaluación, evaluación individual y grupal.

\section{Propuesta de secuencia didáctica}

Las orientaciones descritas tienen por propósito facilitar la elaboración de actividades secuenciadas de trabajo en aula. Las secuencias pedagógicas comprenden a la organización de los contenidos de enseñanza para crear situaciones de aprendizaje que permitan a los estudiantes articular sus conocimientos previos y los nuevos saberes en un sentido significativo.

Diseñar secuencias didácticas para el trabajo en aula y en terreno, demanda el posicionamiento de los docentes en las dimensiones pedagógicas: del saber disciplinar, enfoque pedagógico, interpretación curricular y el enfoque de ciudadanía. La organización de los componentes de las secuencias es una decisión que se ejerce desde la caracterización del contexto sociocultural en el que se desarrolla el acto de enseñanza.

Con todo, en su conjunto, la enseñanza del patrimonio cultural de los derechos humanos, requiere del diseño de situaciones de aprendizajes secuencias, dirigidas por objetivos de aprendizajes contextualizados, que permitan el uso conceptual concreto dentro del territorio, que posicione a los estudiantes como protagonistas de sus aprendizajes y faciliten el desarrollo de capacidades ciudadanas activas.

A continuación, se presentará una de las secuencias pedagógicas que articulan la interpretación dada al contexto sociocultural de la escuela (para qué enseñar), el posicionamiento conceptual en torno al campo de la memoria social y patrimonio (qué enseñar) y las orientaciones didácticas elaboradas a partir de la sistematización de experiencias pedagógicas (cómo enseñar). Lo anterior con el propósito de contar con una panorámica general que ayude al ejercicio docente a la hora de tomar decisiones dentro de su planificación. 
Unidad temática: Las huellas locales del pasado reciente:

Movimiento estudiantil y defensa de los Derechos Humanos en Valparaíso (1980-1989)

La secuencia propuesta para el trabajo pedagógico del ámbito pasado reciente fue estructurada desde la unidad $n^{\circ} 3$ del programa de estudios del nivel de 3ro medio, denominada: "El quiebre de la democracia y la Dictadura Militar". El Aprendizaje Esperado (AE13) comprende a la caracterización de los principales rasgos del Golpe de Estado y de la Dictadura Militar en Chile, incluyendo: La violación sistemática de los Derechos Humanos, la violencia política y la supresión del Estado de derecho.

En la contextualización del aprendizaje esperado, se formula el tema del proyecto: "Las huellas locales del pasado reciente: Movimiento estudiantil y defensa de los Derechos Humanos en Valparaíso (1980-1989)”, que tendrá por objetivo de aprendizaje comprender espacialmente los principales rasgos de la Dictadura Militar en Valparaíso en el periodo 1980-1989: violación y defensa de los Derechos Humanos entre los segmentos juveniles. De esta forma, la contextualización de los contenidos de enseñanza busca materializar la experiencia traumática de la violación de los Derechos Humanos en el espacio local a través de actores sociales generacionalmente cercanos a los estudiantes, conocer las formas de organización estudiantil, las demandas y las estrategias de promoción y defensa de los DD.HH. que promueve una conciencia histórica empática, que reconoce a las "víctimas" como ciudadanos (as) comprometidos con el proyecto de recuperación de la Democracia y destaca las continuidades y cambios de forma y contenido de los movimientos sociales actuales.

El posicionamiento pedagógico en la dimensión conceptual considera el uso de las nociones geográficas de territorio y territorialidad, desde la historia, la noción de testimonio, pasado reciente y relación historia-memoria, y desde la antropología el concepto de identidad cultural, conmemoración y sitios de memoria.

Asimismo, considera en la dimensión de la formación ciudadana la estrategia de ABP para facilitar la comprensión crítica de las nuevas generaciones sobre los sucesos locales acontecidos en el periodo de Dictadura Militar desde sus propios procesos de resignificación a través de un producto final de conmemoración colectiva.

Los objetivos de aprendizajes seleccionados para el desarrollo de las estrategias didácticas, permiten en forma y contenido incorporar el eje de memoria social y el patrimonio cultural local. Si bien resulta ideal el desarrollo de unidades curriculares completas y no contenidos parciales, los temas seleccionados abordan procesos claves en la Historia de Chile que nos interesa dinamizar en el espacio local (representativos de unidades). El principio de adaptabilidad se manifiesta en la capacidad de selección e implementación en los niveles de enseñanza básica y/o enseñanza media que requieran la incorporación de estos temas en la planificación curricular.

La modalidad de trabajo dependerá de la disponibilidad técnica-pedagógica que cuente el establecimiento educacional. A primeras luces, el formato se inscribe en la lógica de un taller teórico-práctico, al articular las herramientas conceptuales al servicio de la dimensión 
procedimental del aprendizaje. Por esta razón, las salidas a terreno fueron planificadas en un doble sentido pedagógico: una experiencia vivencial (reforzar contenidos vistos en las sesiones en aula) y como una actividad experimental (se adquieren nuevos conocimientos desde el acto de descubrimiento).

Con todo, en su conjunto, nuestra propuesta busca rediseñar el trabajo educativo en el área de Historia, Geografía y Ciencias Sociales incorporando la memoria social local, para promocionar nuevas formas de identificaciones con los bienes patrimoniales. Consecuentemente con lo anterior, a continuación se presenta una planificación, considerando un curso de tercer año medio, en la que se aplican los elementos curriculares de Didáctica del Patrimonio Cultural para la enseñanza y aprendizaje de los Derechos Humanos.

\section{CONCLUSIONES}

Se constata la necesidad de proponer un tratamiento articulado entre el saber académico y el conocimiento social, potenciando entre los y las estudiantes el desarrollo de aprendizajes significativos (empatía y pertenencia) para asegurar la salvaguardia consciente de los lugares de memoria desde una ciudadanía activa, lo que se materializa en una propuesta didáctica de los derechos humanos desde la perspectiva patrimonial.

La enseñanza de la historia con memoria cumple un rol clave, en razón de la relevancia que adquiere el tiempo pasado en las representaciones sociales, el marco de las decisiones colectivas se encuentra tensionado por las experiencias y expectativas colectivas. El reconocimiento de un pasado reciente común se sustenta en una serie de estrategias didácticas en, desde y sobre los testimonios (recuerdos), a fin de facilitar acciones de selección, valoración y recreación del patrimonio de los Derechos Humanos basadas en la consolidación en una memoria del nunca más.

La articulación pedagógica desde un enfoque controversial permite jerarquizar los tópicos ciudad educadora, los derechos humanos y patrimonio cultural según el carácter del lugar de memoria y de las acciones de puesta en valor que requieran las ciudadanías, para intensificar el recuerdo y tomar decisiones en un marco de una convivencia pacífica y democrática.

La propuesta responde a las exigencias actuales de la formación escolar en la escena de las sociedades del conocimiento, quienes viven una cultura histórica basada en el pleno acceso a la información sobre el tiempo pasado; sin embargo, producto de la aceleración se han desarrollado débilmente las capacidades cognitivas, procedimentales y ciudadanas para permitir observar, comprender y construir conocimiento histórico genuino.

\section{REFERENCIAS}

Aroca, C. (2017). Didáctica del Patrimonio. Métodos y estrategias para trabajar en Educación. Santiago de Chile: LOM Ediciones. 


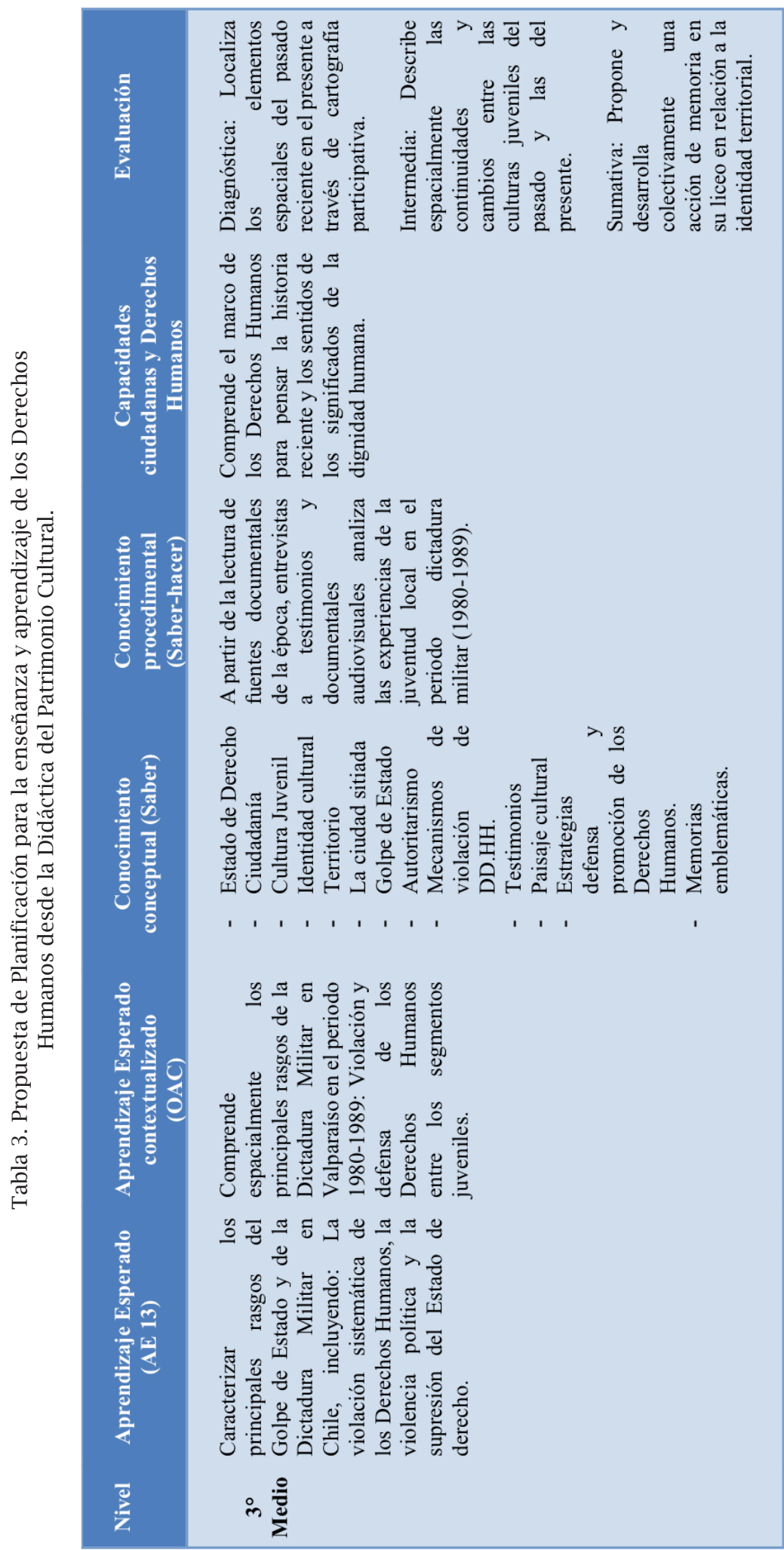




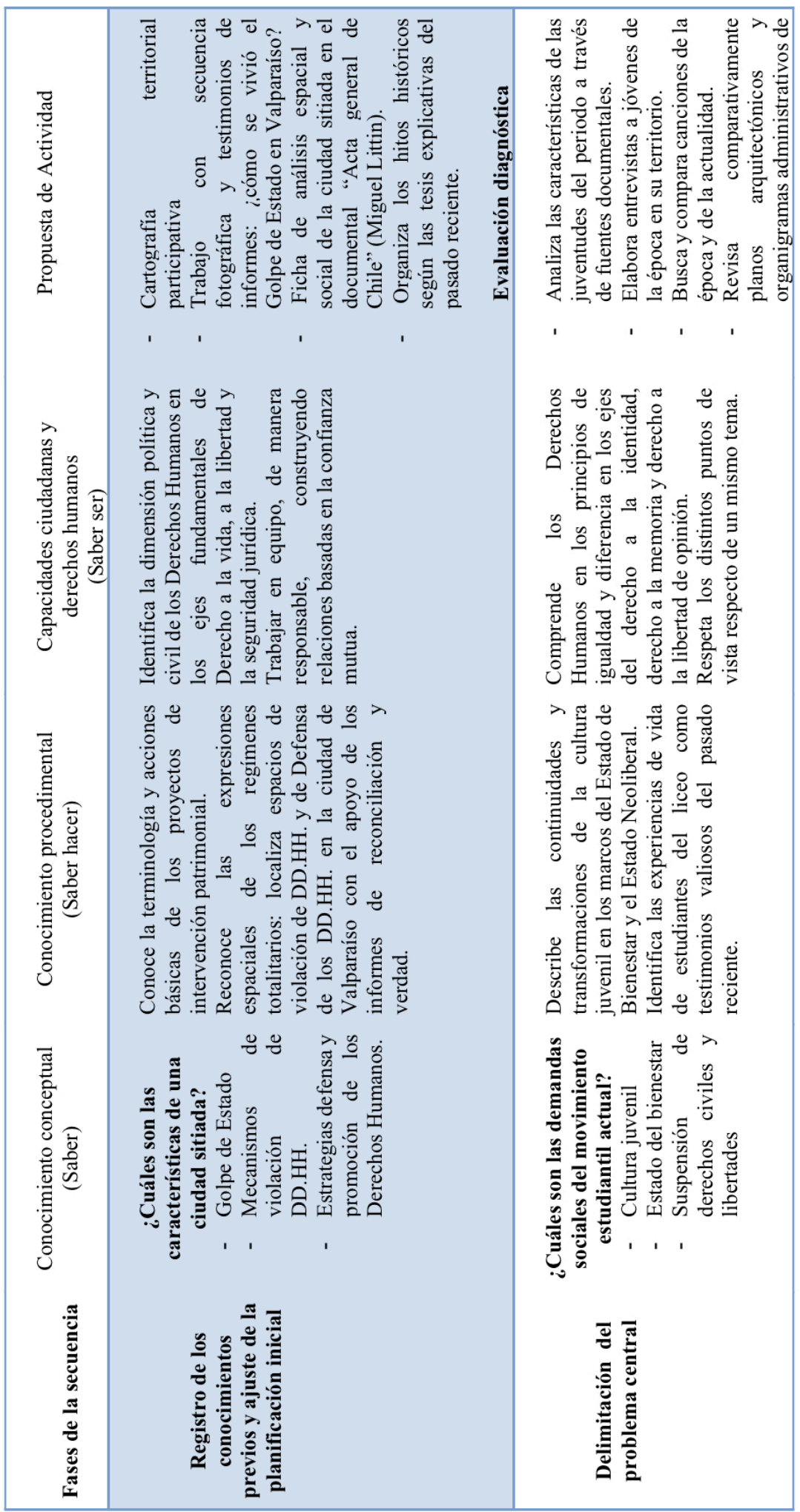




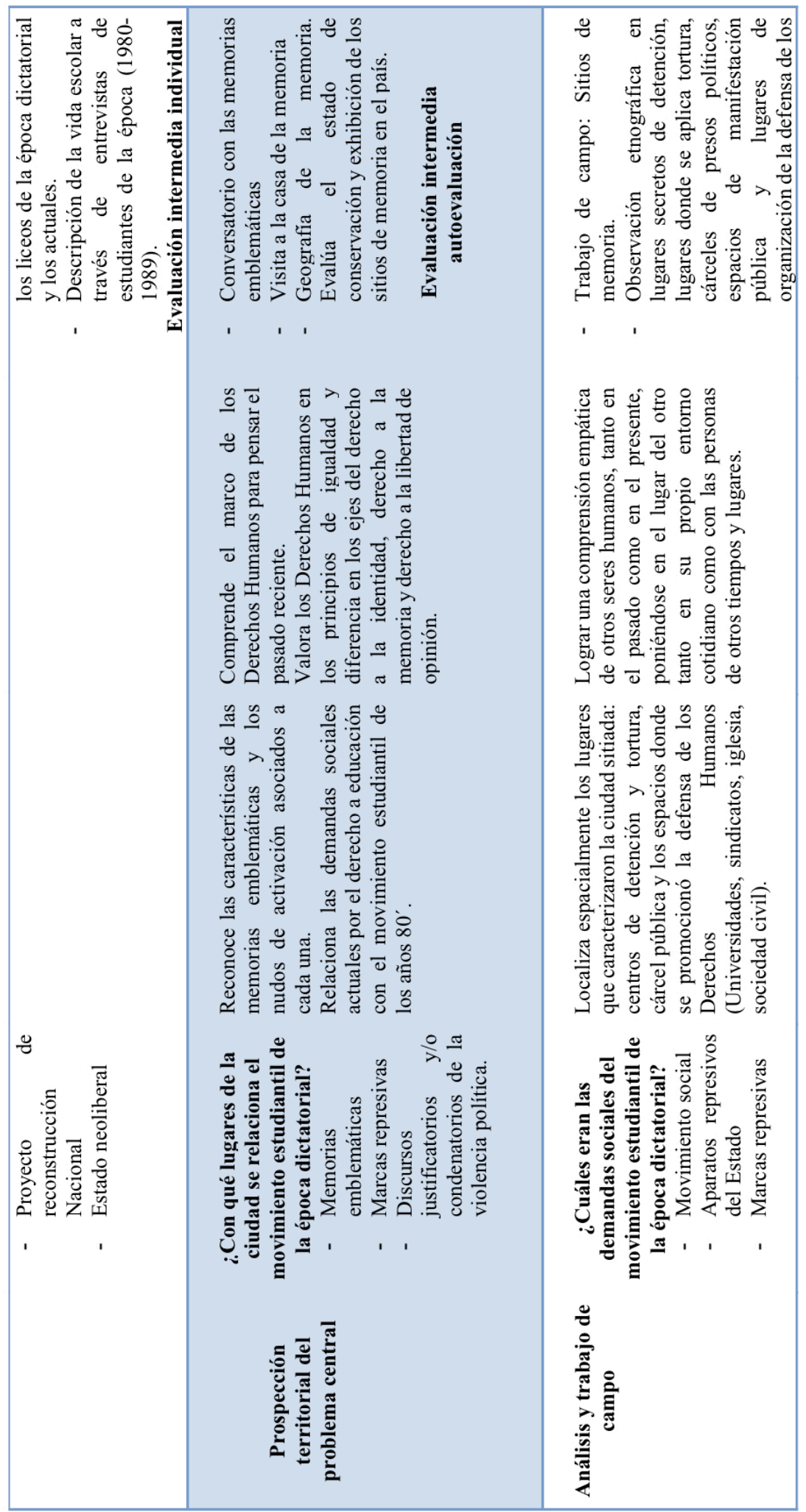


CIUDAD EDUCADORA

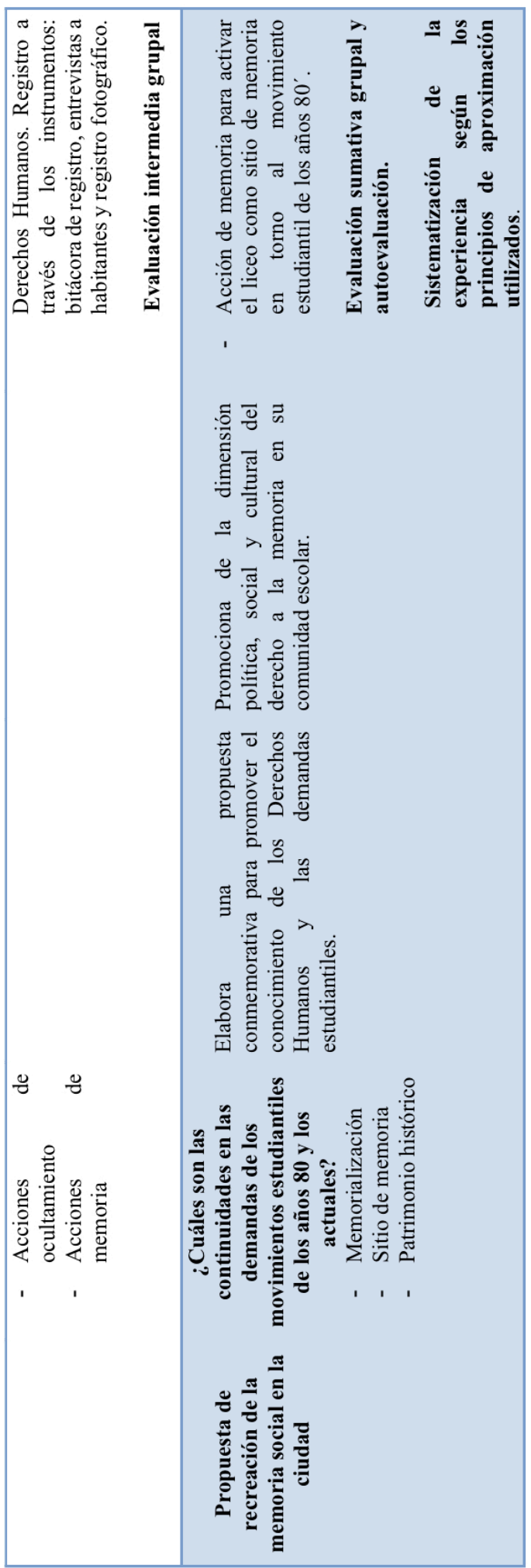

Fuente: Elaboración propia. 
Asamblea General de la Organización de las Naciones Unidas 2005 ONU. Principios y directrices básicos sobre el derecho de las víctimas de violaciones manifiestas de las normas internacionales de derechos humanos y de violaciones graves del derecho internacional humanitario a interponer recursos y obtener reparaciones. Disponible en https://www. ohchr.org/SP/ProfessionalInterest/Pages/RemedyAndReparation.aspx

Biblioteca del Congreso Nacional de Chile. Período 1973-1990. Régimen Militar. Disponible en https://www.bcn.cl/historiapolitica/hitos_periodo/detalle_periodo. html?per=1973-1990

Comisión de Derechos Humanos, ONU (2005). Resolución N²005/66 sobre El Derecho a la Verdad (EEUU, 20/42005) Disponible en http:// ap.ohchr.org/documents/S/CHR/ resolutions/E-CN_4-RES-2005-66.doc

Comisión Interamericana de Derechos Humanos (2009). Informe Anual de la comisión de Derechos Humanos. Disponible en https://www.cidh.oas.org/pdf\%20files/ RELEAnual\%202009.pdf

Comisión Nacional sobre Prisión Política y Tortura. (2004). Informe de la Comisión Nacional sobre Prisión Política y Tortura (Valech I). Disponible en https://bibliotecadigital.indh. $\mathrm{cl} /$ handle/123456789/455

Comisión Nacional de Verdad y Reconciliación. (1991). Informe de la Comisión Nacional de Verdad y Reconciliación Disponible en https://bibliotecadigital.indh.cl/ handle/123456789/170

Congreso Nacional Ley NÚM. 20.911. Crea el Plan de Formación Ciudadana para los Establecimientos Educacionales reconocidos por el Estado Disponible en https://www. leychile.cl/Navegar?idNorma=1088963

Cuesta, R. (2003). Historia, Educación y Didáctica Crítica. Consideraciones Fedicarianas. Disponible en http://www.nebraskaria.es/wp-content/uploads/2016/09/Burgos.pdf

Estepa, J. (2019). Memoria democrática en la construcción de la historia y el patrimonio, textos provisionales [pre-prints]. Debate revista PH Sección Perspectivas 96. Instituto Andaluz del Patrimonio Histórico. Consejería de Cultura.

Gadamer, H-G. (1993). El problema de la conciencia histórica. Madrid: Tecnos.

Jelin, E. (2002). Los trabajos de la memoria. Memorias de la represión. Madrid: Siglo XXI ediciones.

Magendzo, A., \& Pavez, J. (2018). Educando en la Declaración Universal de los Derechos Humanos desde una mirada Controversial, en Pedagogía y Didáctica de la Declaración Universal de los Derechos Humanos a setenta años de su promulgación (1948-2018). En Magendzo y Morales (Eds.), Cátedra en Educación en Derechos Humanos (pp. xx-xx) Santiago: Ediciones Universidad Academia Humanismo Cristiano.

Maturana, C. (2017). Nuevos contextos para la enseñanza de la Historia y las Ciencias Sociales. Aportes de una sistematización de experiencias escolares con uso pedagógico del patrimonio cultural y memoria histórica (tesis de para optar al grado de profesora de 
Historia y Ciencias Sociales). Valparaíso. Universidad de Valparaíso.

Ministerio de Educación. Currículum de la Educación Básica. Objetivos Fundamentales y Contenidos Mínimos Obligatorios. Estudio y Comprensión de la Sociedad. Gobierno de Chile. Actualización 2002. Disponible en http://www.curriculummineduc.cl/docs/ fichas/ed_basica_estudio_y_comprension_de_la_sociedad_decreto_40_mod_230.pdf (Consultado el 28 de octubre de 2018).

Ministerio de Educación (2009). Objetivos Fundamentales y Contenidos Mínimos

Obligatorios de la Educación Básica. Santiago de Chile. Actualización 2009. Disponible en https://www.agenciaeducacion.cl/wp-content/uploads/2013/02/Marco-Curricular-y ctualizacion2009-I-a-IV-Medio.pdf

Ministerio de Educación (2013). Bases Curriculares Educación Básica. Santiago de Chile.

Disponible en https://www.curriculumnacional.cl/614/articles-37136_bases.pdf

Ministerio de Educación. (2002). División de Educación General. Orientaciones para la elaboración de un Plan de Formación Ciudadana, 2015. Disponible en https:// www.mineduc.cl/wp-content/uploads/sites/19/2016/04/DEG-OrientacionesPFCintervenible-AReader_FINAL.pdf

Pagés, J. (2008). El lugar de la memoria en la enseñanza de la historia. Íber. Didáctica de las Ciencias Sociales, Geografía e Historia, 55, 43-53.

Pagés, J., \& Marolla, J. (2018). La historia reciente en los currículos escolares de Argentina, Chile y Colombia. Desafíos de la educación para la ciudadanía desde la Didáctica de las Ciencias Sociales. Historia y Memoria, 17, 153-184.

Prats, J. (1998). El concepto de Patrimonio Cultural. Revista Política y Sociedad. Editores: Universidad Complutense de Madrid. 27.

Rubio, G. (2013). Memoria, Política y Pedagogía: Los caminos hacia la enseñanza del pasado reciente en Chile. Santiago de Chile: LOM Ediciones.

Rüsen, J. (2009). ¿Qué es la cultura histórica?: Reflexiones sobre una nueva manera de abordar la historia. Culturahistórica. [Versión castellana inédita del texto original alemán en K. Füssmann, H. T. Grütter \& J. Rüsen (Eds.), (1994). Historische Faszination. Geschichtskultur heute (pp. 3-26). Keulen, Weimar y Wenen: Böhlau

Seguel, P. (2018). Políticas de protección patrimonial Sitios de Memoria en Chile, 1996-2018. Aproximaciones desde un campo en construcción. Revista Persona y Sociedad, XXXII, 36-97.

Todorov, T. (2000). Los abusos de la Memoria. Barcelona: Paidós Ibérica, S.A.

Trilla, J. (1993). Otras educaciones. Animación sociocultural, formación de adultos y ciudad educativa. México: Anthropos Editorial del Hombre: Universidad Pedagógica Nacional.

UNESCO. (1948). Declaración Universal de los Derechos Humanos. Disponible en https:// es.unesco.org/udhr 